\title{
Using thematic mapping and United Nations Sustainable Development Goal indicator data to investigate environmental factors related to the spread of COVID -19
}

\author{
Jennifer Anderson a , Britta Ricker ${ }^{\mathrm{a}, *}$ \\ aUtrechtUniversity1 j.a.anderson@uu.nl,2b.a.ricker@uu.nl \\ * Corresponding author
}

Keywords: Thematic maps, SDG, COVID-19

The natural environment houses ecosystems that provide a wide variety of essential benefits to humanity including food, water, resources, and climate regulation, all required for healthy human populations. Ecosystems, and the biodiversity they support, can help to regulate the transmission of infectious diseases. These connections, however, are not always obvious. In light of the current global pandemic stemming from Coronavirus-19 (COVID-19), improving our understanding of the relationships between the natural environment and humans could be beneficial in mitigating the impacts of future pandemic incidence, while contributing towards a more sustainable future for the planet.

Research has shown there is a link between biodiversity loss and zoonotic disease transmission (Afelt, Frutos, \& Devaux, 2018; Chan, To, Tse, Jin, \& Yuen, 2013; Millennium Ecosystem Assessment, 2005; Myers et al., 2013). In an effort to identify policies and explore potential relationships between COVID-19 and biodiversity, we turn to the existing United Nations (UN) Sustainable Development Goal (SDG) indicator data. Two of the most relevant SDG indicators available to investigate the relationship between biodiversity and human health related to the COVID-19 outbreak include: 15.1.1: Forest area as a percentage of total land area within a country and Indicator 15.1.2: Proportion of important sites for terrestrial and freshwater biodiversity that are covered by protected areas, by ecosystem type (UNDP, 2019).

Maps can be effective tools for communicating vital relationships between humans and the natural and animal environment. User-friendly maps could help scientists, decision-makers, and the general public alike identify, implement and support policies to encourage biodiversity and ecosystem preservation interventions, and in turn potentially prevent or diminish the severity of another global pandemic. The most appropriate thematic mapping technique depends on the data available and the intended use of the map. In terms of mapping the official UN SDG indicators, the thematic mapping can impact the presentation, and overall message, of certain indicator data (Kraak, Ricker, \& Engelhardt, 2018; Pirani, Ricker, \& Kraak, 2019). With existing indicator data, it is only possible to make choropleth maps since data are aggregated at the national level. Additional datasets are required to offer more localized solutions. Alternatives to choropleth mapping are described here.

Dasymetric mapping depicts quantitative areal data, using ancillary datasets to divide a mapped area into zones of relative homogeneity, with the purpose of portraying data at a finer, localized resolution (Eicher \& Brewer, 2001; Mennis \& Hultgren, 2006). Dasymetric mapping could provide a better form of data presentation for many SDG indicators since it incorporates geographic distribution information and shows where specific phenomena occur.

Dasymetric maps often build upon choropleth maps (Mennis, 2017). For example, with this approach to dasymetric mapping, the map maker could use land cover datasets as ancillary data to reassign the original data to different enumeration units within the original aerial units of a choropleth map (Eicher \& Brewer, 2001), which redistributes the data thus changing the data rates. Since satellite imagery is a form of quantitative areal data, which often ignores anthropogenic demarcations, remote sensing often better represents the true spatial distribution of phenomena (Batista e Silva, Gallego, \& Lavalle, 2013; Langford, 2003; Li \& Zhou, 2018) and can be an appropriate and reliable source of information for ancillary data to include in dasymetric maps.

While investigating dasymetric mapping and its applicability to the SDG indicators, however, we identified an inherent problem with this technique regarding certain indicator data and specifically Indicator 15.1.2: Protected Key Biodiversity Areas (KBAs) since it relies on two anthropogenically-derived datasets, namely protected areas and KBAs. KBAs, as the name suggests, are areas of high biodiversity and the methods to assign these areas are agreed upon by a global community of scientists. The boundaries for these areas are administrative by nature, which makes true dasymetric mapping inherently impossible. Therefore, this project drew inspiration from the principles related to dasymetric mapping to develop maps depicting indicator-delineated boundaries for Indicators 15.1.1 and 15.1.2. The method we apply here uses spatial data, with the goal of producing maps that present the distribution of the indicator data in a more relevant way, in an effort to support conservation decision making at a localized level. This investigation into dasymetric mapping for Indicator 15.1.2 resulted in the development of a novel result of depicting the UN statistics for Indicator 15.1.2 using KBA-delineated boundaries (Figure 1a) compared to the choropleth format typically employed for these statistics. It is important to remember that not all KBAs are protected. This means that large patches of yellow require the most attention in terms of new protective policies in Africa (Figure 1a and 1b). 

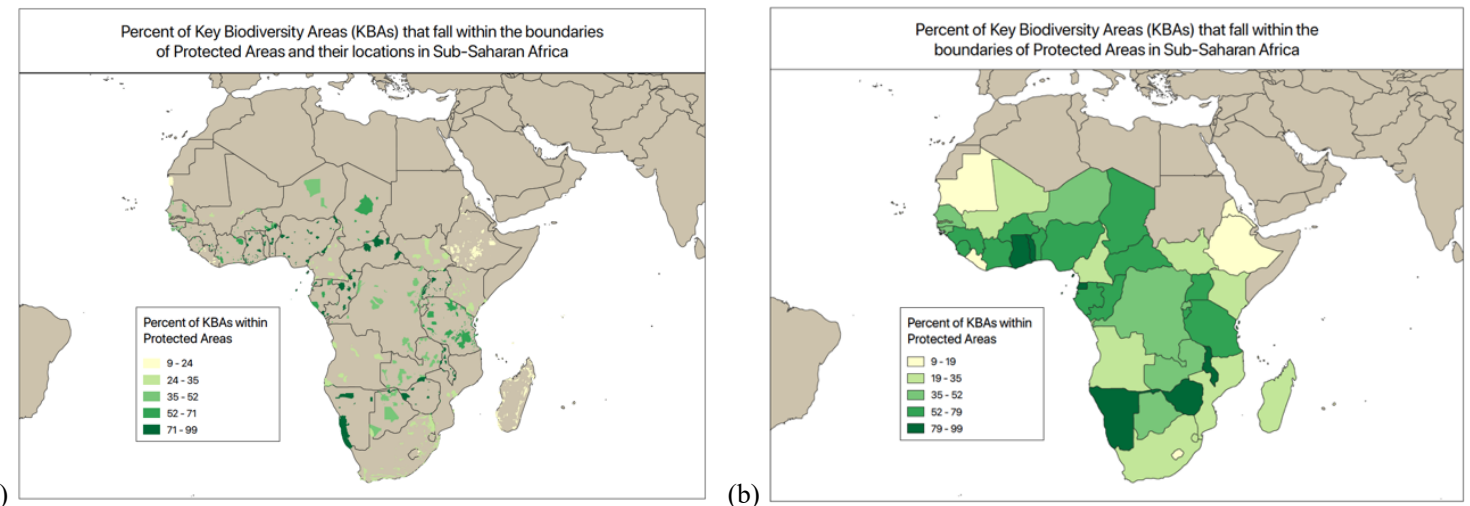

Figure 1. (a) Map depicting the 2019 UN statistics for SDG Indicator 15.1.2: Proportion of KBAs within the boundaries of protected areas for each country in Sub-Saharan Africa, using geographic location data to delineate protected KBA boundaries. (b) Choropleth map depicting the 2019 UN statistics for SDG Indicator 15.1.2: Proportion of KBAs within the boundaries of protected areas for countries in Sub-Saharan Africa.

Indicator 15.1.2, the KBA-delineated maps of this project (Figures 1a, 2a and 2b) depict the locations and distributions of these boundaries precisely and allow map users to identify specific protected KBAs areas. Thus, the map using KBAdelineated boundaries are more suitable for informing conservation-based decision making, rather than traditional choropleth maps.

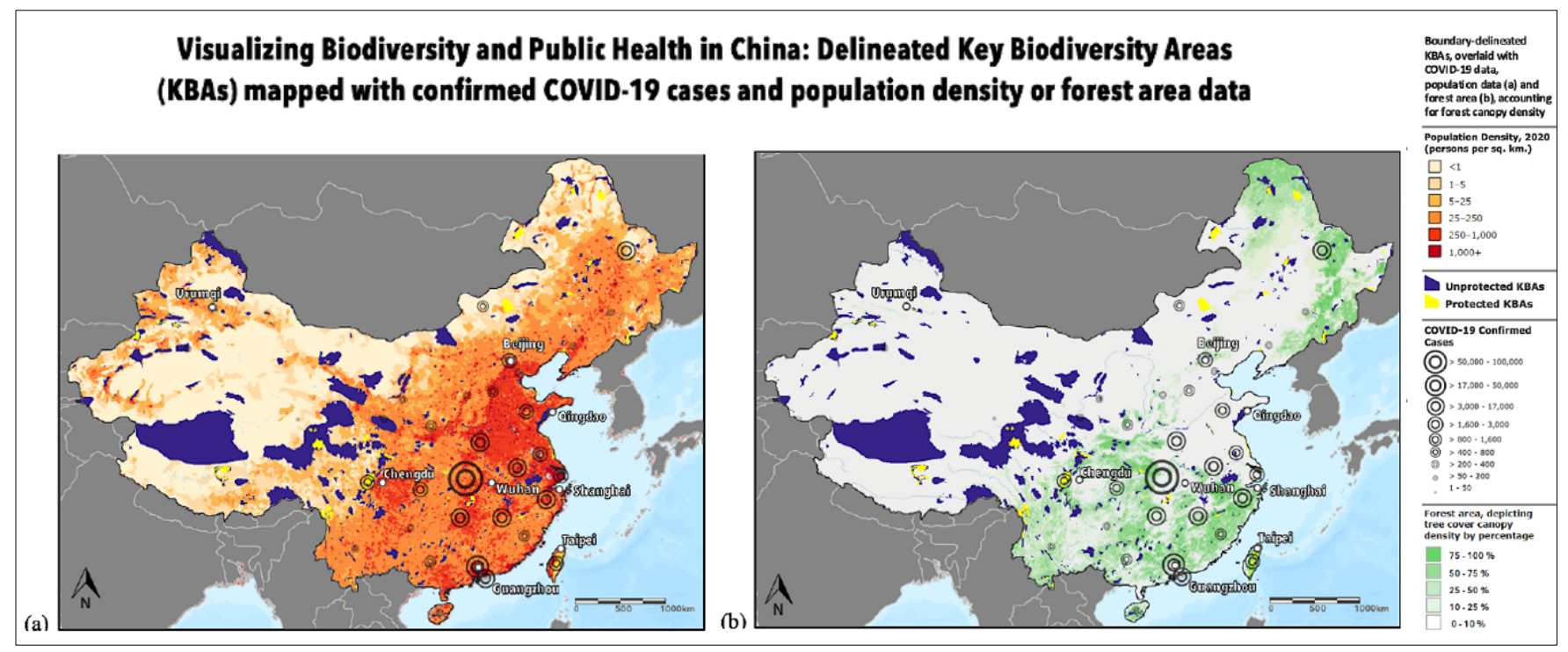

Figure 2. (a) Map depicting SDG Indicator 15.1.2 data, using geographic location data to display unprotected and protected KBAs, overlaid with population data and confirmed COVID-19 cases in China. The map portrays unprotected KBAs in purple and protected KBAs in yellow for China in 2019. Population density estimates for 2020 are displayed with a color gradient from low (light beige) to high density (dark red). (b) Map depicting data for SDG Indicators 15.1.1 and 15.1.2, using geographic location data to display forest area as well as unprotected and protected KBAs, overlaid with confirmed COVID-19 cases in China. The map portrays forest areas from the Hansen et al. (2013) dataset in a light-to-dark color gradient, corresponding to forest canopy density, and displays unprotected KBAs in purple and protected KBAs in yellow for 2019 in China. For both maps, COVID-19 cases as of May 22, 2020 are represented by the black circles and follow a size gradient, with smaller circles representing lower numbers of confirmed cases and bigger circles representing higher numbers of confirmed cases. Web Mercator projection.

Furthermore, the data for Indicator 15.1.1 and 15.1.2 have yet to be mapped with data of the human toll resulting from the COVID-19 pandemic as presented in Figures 2a and 2b. Research has already shown that choropleth mapping may not be the most suitable format for COVID-19 data presentation (Gao, Zhang, Wu, \& Wang, 2020). In addition, one study found that dasymetric mapping offers a more accurate approach and is preferable for presenting spatially-explicit data when assessing population distribution for the purposes of health exposure studies (Requia, Koutrakis, \& Arain, 2018). Therefore, drawing on concepts related to dasymetric mapping and generating maps with indicator-delineated boundaries may provide insights into the relationship between biodiversity and population data as well as contribute towards the ongoing research into effective mapping methods for COVID-19.

The resulting multivariate maps displaying Indicators 15.1.1 and 15.1.2 using realistic boundary data for forest areas and protected KBAs allow for comparison of these indicators to public health statistics, such as COVID-19 data, within a particular country. Such maps could offer valuable visualizations of such data for informing conservation or public healthoriented decision-making and could contribute to preventing or mitigating the impact of future infectious disease outbreaks. 
References:

Afelt, A., Frutos, R., \& Devaux, C. (2018). Bats, Coronaviruses, and Deforestation: Toward the Emergence of Novel Infectious Diseases? Frontiers in Microbiology, 9(APR), 702. https://doi.org/10.3389/fmicb.2018.00702

Batista e Silva, F., Gallego, J., \& Lavalle, C. (2013). A high-resolution population grid map for Europe. Journal of Maps, 9(1), 16-28. https://doi.org/10.1080/17445647.2013.764830

Chan, J. F. W., To, K. K. W., Tse, H., Jin, D. Y., \& Yuen, K. Y. (2013, October 1). Interspecies transmission and emergence of novel viruses: Lessons from bats and birds. Trends in Microbiology. Elsevier Current Trends. https://doi.org/10.1016/j.tim.2013.05.005

Eicher, C. L., \& Brewer, C. A. (2001). Dasymetric mapping and areal interpolation: Implementation and evaluation. Cartography and Geographic Information Science, 28(2), 125-138. https://doi.org/10.1559/152304001782173727

Gao, P., Zhang, H., Wu, Z., \& Wang, J. (2020). Visualising the expansion and spread of coronavirus disease 2019 by cartograms. Environment and Planning A: Economy and Space, 52(4), 698-701. https://doi.org/10.1177/0308518X20910162

Kraak, M. J., Ricker, B., \& Engelhardt, Y. (2018). Challenges of Mapping Sustainable Development Goals Indicators Data. ISPRS International Journal of Geo-Information, 7(12), 482. https://doi.org/10.3390/ijgi7120482

Langford, M. (2003). Refining methods for dasymetric mapping using satellite remote sensing. In V. Mesev (Ed.), Remotely Sensed Cities. Boca Raton: CRC Press | Taylor \& Francis Group.

Li, X., \& Zhou, W. (2018). Dasymetric mapping of urban population in China based on radiance corrected DMSP-OLS nighttime light and land cover data. Science of the Total Environment, 643, $1248-1256$. https://doi.org/10.1016/j.scitotenv.2018.06.244

Mennis, J. (2017). Dasymetric Mapping. In International Encyclopedia of Geography: People, the Earth, Environment and Technology (pp. 1-10). Oxford, UK: John Wiley \& Sons, Ltd. https://doi.org/10.1002/9781118786352.wbieg0443

Mennis, J., \& Hultgren, T. (2006). Intelligent Dasymetric Mapping and Its Application to Areal Interpolation. Cartography and Geographic Information Science (Vol. 33).

Millennium Ecosystem Assessment. (2005). Ecosystems and Human Well-being: Biodiversity Synthesis. Washington D.C.

Myers, S. S., Gaffikin, L., Golden, C. D., Ostfeld, R. S., Redford, K. H., Ricketts, T. H., ... Osofsky, S. A. (2013). Human health impacts of ecosystem alteration. PNAS, 110(47), 18753-18760. https://doi.org/10.1073/pnas.1218656110

Pirani, N., Ricker, B. A., \& Kraak, M. J. (2019). Feminist cartography and the United Nations Sustainable Development Goal on gender equality: Emotional responses to three thematic maps. The Canadian Geographer / Le Géographe Canadien, 64(2), 184-198. https://doi.org/10.1111/cag.12575

Requia, W. J., Koutrakis, P., \& Arain, A. (2018). Modeling spatial distribution of population for environmental epidemiological studies: Comparing the exposure estimates using choropleth versus dasymetric mapping. Environment International, 119, 152-164. https://doi.org/10.1016/j.envint.2018.06.021

United Nations Development Programme [UNDP]. (2019). Goal 15: Life on land. Retrieved March 1, 2019, from https://www.undp.org/content/undp/en/home/sustainable-development-goals/goal-15-life-on-land.html 